\title{
Rainbows, Time Zones, and Other Mind-Dependent Objects: Making Sense of the Relevant Notions of "Mind-Dependence" in the Debate between Metaphysical Realists and Antirealists
}

\author{
Deborah C. Smith \\ Kent State University, Kent, USA \\ Email: dcsmith1@kent.edu \\ Received November $9^{\text {th }}, 2011$; revised December $14^{\text {th }}, 2011$; accepted December $21^{\text {st }}, 2011$
}

\begin{abstract}
In a recent article, Sam Page distinguishes four kinds of mind-(in)dependence: ontological, causal, structural, and individuative. He argues that, despite the fact that the metaphysical realism/antirealism debate has been frequently characterized as a debate between those who accept and those who deny that the world is causally and/or structurally dependent on minds, many antirealists are primarily interested in defending the claim that the world is individuatively mind-dependent. In this article, I critically examine these differing senses of "mind-dependence" highlighting ways in which they remain ambiguous and identifying various entailment relations between them. I argue that there is reason to believe that ontological dependence, structural dependence, and the only sort of individuative dependence that is relevant to the metaphysical debate are coextensive notions. As such, any argument that succeeds in establishing that it is incoherent to suppose that everything is ontologically and/or structurally dependent thereby establishes the incoherence of metaphysical antirealism.
\end{abstract}

Keywords: Realism; Antirealism; Mind-Dependence

\section{Introduction}

There seems to be little doubt that, since at least the middle of the last century, there has been a lively debate (or rather a family of lively debates) between proponents of views dubbed "realism" and "antirealism" respectively revolving around the question of whether or not a given set of objects, properties/ relations, facts, truths, etc. is significantly dependent on the existence and activities of (human or other finite) minds. The debate between mathematical realists and antirealists is plausibly construed as a debate over whether mathematical objects, properties or truths are somehow constructed (as opposed to discovered) via our mathematical theories and the development of mathematical proofs. The debate between sortal realists and antirealists centers on the question of whether there are real kinds in nature independent of our categorizing or sorting of individuals into various kinds. Scientific realists and antirealists debate about whether scientific laws hold or whether the unobservable entities postulated by our best scientific theories exist independent of our scientific theorizing. In addition to these localized realism/antirealism debates, there is the more global metaphysical debate concerning whether or not there is anything at all that is mind-independent. While it is clear that the notion of mind-dependence plays an important role in these and other realism/antirealism debates, ${ }^{1}$ the notion of mind-depend-

\footnotetext{
${ }^{1}$ A notable exception to the claim that any given realism/antirealism debate trades on the question of mind-dependence is the debate between moral realists and antirealists. It seems to me that the moral realist can and should allow that moral properties, principles, or truths are dependent on the existence of rational, sentient creatures. If there were no creatures with minds, the world would plausibly be a completely amoral place. Instead, the debate over moral realism seems to trade on whether there are any universal or objective moral truths, principles, or prescriptions.
}

ence itself remains less than clear. This paper will examine the various notions of mind-dependence that are germane to the global debate between metaphysical realists and antirealists.

\section{Mind-Dependence and the Debate between Metaphysical Realism and Antirealism}

In "The Case for Metaphysical Realism" I defended a realist view that I called modest metaphysical realism. As defined there, modest metaphysical realism (hereafter simply "metaphysical realism") is the conjunction of two theses (Smith, 2002: p. 411):

1) The world does not depend on the existence or activities of minds for its ontological status.

2) The world has some structure(s) that is(are) mind-independent.

Denying either thesis yields a (near) global version of metaphysical antirealism according to which any and all structure in the world and/or the very ontological status of the world is mind-dependent. In defense of metaphysical realism, I argued that neither the ontological status nor all of the structure of minds themselves could be mind-dependent (Smith, 2002: pp. 414-415).

Sam Page has suggested that my argument for metaphysical realism misses the mark because I (and others) have failed to appreciate the relevant sense of "mind-dependent" at issue in the (or better, one significant) contemporary debate between realists and antirealists (Page, 2006: p. 327). Page himself distinguishes four kinds of mind-(in)dependence: ontological, causal, structural, and individuative. He argues that, despite the fact that the contemporary realism/antirealism debate has been frequently characterized as a debate between those who accept and 
those who deny that the world ${ }^{2}$ is causally and/or structurally dependent on human minds (Page, 2006: pp. 326-327), many notable antirealists (he cites Richard Rorty, Hilary Putnam, and Nelson Goodman) are primarily interested in defending the claim that the world is individuatively dependent on us (Page, 2006: pp. 330-332).

While I'm inclined to stand by the cogency of my earlier argument as well as its relevance to the contemporary debate ${ }^{3}$ (whose opponents I will continue to call "metaphysical realists" and "metaphysical antirealists" respectively), I agree with Page that the crucial notion of mind-dependence is far from clear. Indeed, the notion is sufficiently ambiguous that I have frequently found myself disturbed by a sense that the metaphysical realist and antirealist were merely talking past one another. Even so, I'm inclined to believe that there is a meaningful debate to be engaged in here and that additional work to disambiguate the relevant sense of "mind-dependence" is needed to better articulate what is at issue - let alone make any headway-in that debate.

\section{Disambiguating "Mind-Dependence"}

In "The Case for Metaphysical Realism", I suggested that the claim that something $\mathrm{X}$ was mind-dependent could be glossed by a counter-factual conditional of the following form: " $\mathrm{X}$ would not exist and have the features that it does if there were no minds" (Smith, 2002: p. 416). An obvious problem with this counter-factual gloss on the relevant sense of "mind-dependence" is that when " $X$ " is replaced by "minds", the result is an instance of the trivially true counter-factual form: " $\mathrm{X}$ would not exist and have the features that it does if there were no Xs". It might prima facie appear that my case for metaphysical realism is rendered incoherent. To address this concern, I argued that there was an ambiguity in the claim that minds are mind-dependent. I wrote:

Consider the following two claims:

1) Trees are mind-dependent entities. That is, a tree would not exist and have the features that it does if there were no minds.

2) Trees are tree-dependent entities. That is, a tree would not exist and have the features that it does if there were no trees.

The first claim is a nontrivial claim about trees. ... The second claim is merely an instance of the trivial claim that nothing of a kind $\mathrm{K}$ can exist and have the features that it does unless there is at least one instance of a given kind $\mathrm{K}$

\footnotetext{
${ }^{2}$ In several places, Page seems to limit his unqualified use of "realism" and "antirealism" to views that focus on the question of whether or not the entire natural world is mind-dependent. (See especially Page, 2006: p. 321). However, throughout the article, he considers other versions of realism and antirealism some of which are more global in nature and some of which are more restricted.

${ }^{3}$ My reasons for so doing will become clearer below. Here let me say that, if it turns out (as Page suggests) that Putnam, Rorty, and/or Goodman would accept metaphysical realism in my sense, I would be content. However, I seriously doubt that there are none but strawmen who would be inclined to deny theses 1) and/or 2) of metaphysical realism.

${ }^{4}$ More precisely, ontological dependence (rather than causal, structural or individuative dependence) seems to be the notion of mind-dependence central to thesis a) of the version of metaphysical realism that I have defended: the world does not depend on the existence or activities of minds for its ontological status. Structural dependence is more clearly at issue in thesis b) of metaphysical realism: that the world has some structure that is mindindependent.
}

(namely itself) ...As such, it is a trivial claim that no one would reject.

Now consider this third claim:

3) Minds are mind-dependent entities. That is, a mind would not exist and have the features that it does if there were no minds.

I want to suggest that this claim is ambiguous between an utterly trivial reading á la 2) above and a nontrivial reading á la 1) above. The proponent of [metaphysical realism] can and should accept c) on its trivial reading. It is the nontrivial reading of 3 ) that a would-be opponent of [metaphysical realism] is committed to accepting. And it is this nontrivial reading of 3 ) that the proponent of [metaphysical realism] takes himself to have shown to be incoherent... (Smith, 2002: p. 416).

Recognizing the need to be more precise concerning what is meant by "mind-dependence" and "mind-independence", I suggested that a fruitful first step would be to begin by examining cases in which both the metaphysical realist and antirealist would agree that an aspect of the world was significantly mind-dependent (Smith, 2002: p. 418).

Consider, as one such putative example a rainbow. A rainbow has a definite stripy character. Although, for example, yellow and green may blur a bit where they meet, there seems to be a finite number of distinct stripes in a rainbow. But of course, the ranges of wavelengths of light... constitute a smooth spectrum; the light spectrum (visible as well as nonvisible) possesses no distinct stripes. The stripes of the rainbow (and perhaps the rainbow itself) are, it seems to me, a paradigm case of aspects of the world that depend for their existence and structure on perceivers, and hence, more generally on minds. ... It seems to me that such putative entities as time zones or hours are mind-dependent in a way significantly different (and stronger) from the stripes of a rainbow. Chairs and other artifacts are mind-dependent in a still different (weaker) sense (Smith, 2002: p. 418).

In "The Case for Metaphysical Realism", I was able to do no more than provide the brief, thumbnail sketch above of how an attempt to disambiguate the relevant sense of "mind-dependent" might proceed. In many ways, Page's article takes up where my thumbnail sketch left off. Despite the fact that Page makes considerable headway in the endeavor, I believe that there is much more work that needs to be done. In what follows, I will critically examine the differing senses of "mind-dependence" presented by Page highlighting ways in which they remain ambiguous and identifying various entailment relations between them. I will argue that three of the four senses of "mind-dependence" identified by Page yield co-extensive classes of mind-dependent objects.

\section{Ontological Dependence and the Debate between Metaphysical Realism and Antirealism}

Of the four types of mind-dependence Page identifies, ontological dependence seems to most closely approximate the sort I take to be germane to the debate between metaphysical realists and antirealists. ${ }^{4}$ Page too is initially inclined to give a counter-factual analysis of the concept of ontological dependence: "Something is ontologically dependent on us if our ceas- 
ing to exist would immediately cause it to cease to exist" (Page, 2006: p. 322). As before, the counter-factual analysis serves to masks the ambiguity in and seemingly renders trivial the claim that minds themselves are ontologically dependent. However, Page goes on to examine putative examples of objects that are ontologically dependent (money, national borders, tax laws, and other "social realities") as well as putative examples of objects that are ontologically independent (mountains, rocks and other "brute physical realities"). In doing so, he is able to articulate a significant way in which an object (or kind of object) might be ontologically dependent on minds:

Things like money, national borders, tax laws, and speed limits - which are sometimes called social realities - are ontologically dependent on people, since if all people went out of existence, they would immediately follow. Their very being is generated and sustained by our collective agreement and social practices (Page, 2006: p. 322).

Engaging in various social practices (including the practice of agreeing or disagreeing) is clearly something that we do qua creatures with minds. So, anything that is generated by and depends for its continued existence upon our engaging in various social practices is clearly mind-dependent in a significant way.

While, I'm inclined to agree that money, national borders, tax laws, and speed limits are ontologically dependent for the reason Page cites, I think that his focus on social realities suggests too narrow a scope for the concept of ontological dependence, at least if that concept is to be at all relevant to the debate between metaphysical realists and anti-realists. To use a now familiar example, it seems to me that the stripes in a rainbow (if not the rainbow itself $f^{5}$ ) are generated by and depend for their continued existence upon on minds. If humans (and other species of animals) were to cease to exist, sunlight would no doubt continue to refract in moisture laden air, but rainbows (if they continued to exist at all) would no longer have stripes. ${ }^{6}$ For this reason, I'm inclined to say that the stripes of a rainbow are ontologically dependent. However, what generates and sustains the stripes of a rainbow is not our collective agreement and social practices. Instead, the stripes of a rainbow are generated and sustained (at least in part) by our perceptual apparatus. Perceiving - at least if that is to include the conscious experience of what is perceived-is again something we do qua creatures with minds. So again, anything that is generated by and depends for its continued existence upon our perceptual apparatuses or the perceptual apparatuses of other animals is significantly mind-dependent.

Just as it is plausible to suggest that mountains and rocks (and moisture laden air) are not generated by nor do they de-

\footnotetext{
${ }^{5}$ Whether or not the rainbow itself is generated by and depends for its continued existence upon minds depends on whether we take rainbows to be inherently striped objects. If we do, the rainbow itself is ontologically dependent. If we take the inherently bowed structure but not the stripes to be essential to a rainbow, the rainbow itself is plausibly taken to be ontologycally independent. Black and white photographs are able to capture the illuminated arc of a rainbow (though not the stripes) and presumably would continue to do so if humans suddenly ceased to exist.

${ }^{6}$ This is analogous to Page's claim about social realities. Claiming that social realities are generated and sustained by our social practices "is not to say that the physical things that get counted as money and national borders, for instance, would go out of existence if all people did, but just that those physical things would no longer count as money or national borders" (Page, 2006: p. 322).
}

pend on our social practices, it is plausible to suggest that mountains and rocks are not generated by nor do they depend on our perceptual apparatuses. They are ontologically independent in both respects. The central argument of "The Case for Metaphysical Realism" is that, whatever is true of money or the stripes of a rainbow, minds cannot be ontologically dependent in either way. If there were no minds, there would be no social practices to generate or sustain minds in the way that money or national borders are generated and sustained. If there were no minds, there would be no conscious perceivers to generate or sustain minds in the way the stripes of a rainbow are generated and sustained. The challenge to the metaphysical antirealist that I presented in "The Case for Metaphysical Realism" is to more fully articulate the ways in which something might be ontologically dependent on minds and to identify a way in which it is coherent to suppose that minds themselves might be ontologically dependent on minds.

Page is inclined to disagree with my claim that ontological dependence is what is at stake in contemporary metaphysical realism/antirealism debates.

Radical Idealism is an apt name for the thesis that all reality is ontologically dependent on us-that if all people ceased to exist, everything else would consequently cease to exist. Few if any academic philosophers, with the notable exception of Berkeley, defend or are alleged to defend something akin to this view (Page, 2006: p. 323).

$\mathrm{He}$ is no doubt correct that contemporary metaphysical antirealists are disinclined to share the view of Berkeley or of nineteenth-century absolute idealists. What is less clear is whether what they do have to say entails some other form of global ontological dependence. To answer that question, we must get clearer about the notion of ontological dependence and the entailment relations in which it stands to other forms of minddependence.

\section{Causal Dependence and the Debate between Metaphysical Realism and Antirealism}

While Page himself has little more to say about ontological dependence, the concept is perhaps more clearly articulated by way of contrast with his notions of causal, structural, and individuative dependence. Page again initially defines causal dependence counter-factually but follows up with a hint of a non-counter-factual account in terms of our making various things or causing them to exist. "If people had never existed, then physical things like baseballs, skyscrapers, and lamps would never have existed, since we make these things. Such manufactured realties are causally dependent on us, since we caused them to exist" (Page, 2006: p. 323). Despite the fact that baseballs and skyscrapers are causally dependent on us, Page notes that they are plausibly taken to be ontologically independent of us. Whatever our hand in generating these objects, we do not appear to sustain them in any relevant sense (Though of course we are capable of destroying them). This highlights the fact that what is crucial to the concept of ontological dependence is not that ontologically dependent objects are generated by us - this they share in common with causally dependent objects. Rather, aspects of the world that are ontologically dependent on us are, presumably unlike baseballs and skyscrapers, inherently dependent on our existence and activities as creatures with minds for their continued existence. 
Since it is not incoherent to suppose that objects such as baseballs, while causally dependent on us, are ontologically independent of us, it seems clear that causal dependence does not entail ontological dependence. But what of the converse? Page himself claims that "[i]t is presumably the case that all things that are causally independent of us are ontologically independent as well" (Page, 2006: p. 323). But of course, for this claim to hold, its contrapositive must also hold: all things that are ontologically dependent on us are causally dependent on us. Whether or not that is the case depends on how broadly we construe causal dependence.

While even a minimally adequate exploration of the notion of causality is well beyond the scope of this discussion, I think it is safe to say that causality is generally construed as a relation between events or types of events. In what follows, I will largely remain neutral concerning what sort of relation between events constitutes a causal relation. I will instead explore different ways of construing causal dependence that differ with respect to what kinds of events are taken to be possible relata of the causal relation. The paradigm instances of causal relata are purely physical events: events involving only physical realities. Here I want to construe "physical reality" fairly broadly to include both the realities postulated by our best scientific theories (such as electrons and quarks, but also molecules, proteins, chromosomes, etc.), as well as macro-physical objects (such as mountains, stars, baseballs, and skyscrapers) recognized by commonsense.

One way of construing the notion of causation is to hold that physical events exhaust the field of the causal relation. On such a view, mental events are able to stand in causal relations (either as cause or effect) only if mental events are a subset of physical events. On this construal of causation, if mental events are not physical events, there is no sense of "mind-dependence" that genuinely involves causation. However, we have already seen that ontological dependence is a significant sense of "mind-dependence". So, if physical events exhaust the field of the causal relation and mental events are not a subset of the physical events, then it follows (contra Page) that ontological dependence does not entail causal dependence. In the discussion that follows, I will consider the case in which mental events do constitute a (proper) subset of the physical events.

It is worth noting at this point that not every event that is physically caused in whole or in part by us is caused by us qua creatures with minds. The examples of causally dependent objects cited by Page (baseballs, skyscrapers, lamps) are importantly all examples of artifacts. Artifacts are intentionally made by us to serve some sort of purpose. Having intentions and purposes are clearly things we do qua creatures with minds. However, artifacts are only a proper subset of the things created by us. As I walk outside on a sunny day, I cause a shadow to be formed. As I live over time in my home, I create numerous dust bunnies. But shadows and dust bunnies are not things that I

\footnotetext{
$\overline{{ }^{7} \text { It is also worth noting that not every object we cause to exist qua creatures }}$ with minds is properly thought of as an artifact. While money, time zones, and other social realities may well be something that we intentionally create to serve a purpose, I am somewhat disinclined to call them artifacts. Moreover, the stripes of a rainbow are not (generally) created intentionally by us to serve any purpose. We simply find ourselves perceiving the stripes of a rainbow at certain times in certain locations at least prima facie in much the same way we find ourselves perceiving mountains and rocks. While there is some sense in which we cause the stripes of a rainbow to exist (our perceptual apparatuses are a significant part of the causal explanation), the rainbow's stripes are clearly not artifacts.
}

intentionally cause (indeed, I would prefer not to cause dust bunnies). A creature otherwise like me but without a mind would still cast shadows and cause dust bunnies as it moved about its environment. These items would not seem to be mind-dependent in any significant way. ${ }^{7}$

If causal dependence is to be taken as a species of mind-dependence, then the notion of causal-dependence should not be so broadly construed so as to include shadows and dust bunnies as causally dependent realities. Were (purely physical) causal dependence to be the sort of mind-dependence at issue in the metaphysical realism/antirealism debate, it would follow (absurdly) that the existence of dust bunnies constitutes a sufficient reason for denying metaphysical antirealism. I submit that this result gives us reason to agree with Page that causal dependence construed in terms of purely physical causation is not germane to the metaphysical debate (This result is not surpriseing. I am aware of no metaphysical antirealist who is inclined to claim that the world and all of its structure is made by us in the way we make baseballs or other artifacts). Given that ontologycal dependence is plausibly thought to be germane to the metaphysical debate, we once again have reason to disagree with Page that ontological dependence entails causal dependence.

But perhaps there is a role for causal dependence to play in the debate between metaphysical realists and antirealists if we construe causal dependence in such a way that the causal relata are not explicitly limited to physical realities and explicitly deny that mental events (at least the ones involved in causal dependence) are a species of physical event. The problem that we face in this case is that, divorced from the purely physical setting at which it is most at home, the notion of causation and with it the distinction between causal dependence and the other varieties of mind-dependence identified by Page becomes quite murky.

\section{Structural Dependence and the Debate between Metaphysical Realism and Antirealism}

A third sense of "mind-independence" identified by Page is what he calls "structural independence".

Something is structurally independent of us if it has a structure independent of how we say it is structured. Mountains are structured independent of us, since they would have many of the physical features and characteristics they do had we never existed (Page, 2006: p. 325).

At first blush, it might seem as if Page would want to cite objects that are causally dependent on us as examples of objects that are structurally dependent. After all, baseballs would not have had the physical features and characteristics that they do had we never existed. Further, the structure of a baseball very much depends on how those who make up the rules of baseball say a baseball is to be structured. However, once created, baseballs (like mountains) have a structure that is quite independent of what we believe or say about how they are structured. Instead, Page states that "Something would be structurally dependent on us if it were totally amorphous and we (somehow) imposed all structure onto it" (Page, 2006: p. 325).

Initially, Page cites clouds as possible examples of items that are structurally dependent since they are somewhat amorphous and it is we who see familiar shapes and patterns in them (Page, 2006: pp. 325-326). However, he is quick to point out that clouds are not really good examples of structurally dependent 
objects since they do have an independent structure.

Clouds, for instance, are comprised of certain molecules and have properties independent of what we think and say about them. It is likely that there are no natural realities that are completely structurally dependent on us... (Page, 2006: p. 326).

To be genuinely structurally dependent, an object would have to be totally amorphous so to speak all the way down so that it was we who imposed any and all structure on the object.

Structural dependence is the sort of mind-dependence I had in mind when formulating thesis b) of metaphysical realism: that the world has some structure(s) this is(are) mind-independent (Smith, 2002: p. 411). Given that I took metaphysical realism to be the conjunction of two theses, any view that denied thesis b) alone would count as a version of metaphysical antirealism. However, as I noted in "The Case for Metaphysical Realism" (Smith, 2002: p. 414), it is far from clear that the notion that something could have independent ontological status but be totally amorphous is even coherent. Page himself notes that even if reality were "at base a fluid, undifferentiated continuum," it would still be structurally independent of us (Page, 2006: p. 328). It seems far more probable that, if anything is structurally dependent on us, that is due to the fact that it is ontologically dependent on us.

The example of a rainbow's stripes is again instructive here. A rainbow has a definite stripy structure that is imposed on reality by our perceptual mechanisms. However, it isn't as if the rainbow exists with a totally amorphous structure prior to our imposition of stripes onto it. Rather, our perceptual mechanisms interacting with an external portion of the world that presumably has independent structure give rise to the stripes of the rainbow. I believe that similar things could be said about the structure of time zones, money, and other social realities that are ontologically dependent on us. This suggests that structural dependence entails ontological dependence. Since it is difficult to see how something could have any independent structure at all were it to lack independent ontological status, I would suggest that something is structurally dependant if and only if it is ontologically dependent.

In rejecting structural dependence as relevant to the metaphysical realism/antirealism debate, Page does not seem to consider the possibility that it might stand or fall with ontological dependence. ${ }^{8}$ He seems only to consider the possibility that there would be some aspect of reality that has independent ontological status but which is amorphous and onto which we impose all structure. Whether or not structural dependence (and with it ontological dependence) is germane to the metaphysical debate will depend heavily on its relation to the type of mindindependence Page does take to be relevant: individuative dependence.

\section{Individuative Dependence and the Debate between Metaphysical Realism and Antirealism}

The final sense of "mind-independence" described by Page (and, according to him, the most relevant to the contemporary realism/antirealism debate) is individuative independence. "To

\footnotetext{
${ }^{8}$ Though to be sure he does suggest, contrary to what I want to maintain, that ontological dependence is not relevant to the contemporary metaphysical realism debate when he notes that few if any contemporary philosophers would be willing to accept radical idealism. (See Page, 2006: p. 323).
}

say that the natural world is individuatively independent of us is to say that it is divided up into individual things and kinds of things that are circumscribed by boundaries that are totally independent of where we draw the lines" (Page, 2006: p. 327). While the question of whether or not there are real kinds independent of us is the heart of the historical debate between sortal realists and nominalists, it is (or so it seems to me) of dubious relevance to the contemporary debates between metaphysical realists and antirealists. As such, I will focus exclusively on the element of individuative dependence/independence that involves the individuation of the world into discrete things. As examples of objects that are plausibly taken to be individuatively independent of us, Page cites the moon, individual apples, grizzly bears, and pearls. As prime examples of things that are individuatively dependent on us, Page cites individual constellations.

We individuate the night sky into constellations. We, or more specifically our ancestors, determined which stars comprise which constellations. We can come up with new constellations whenever we like simply by pointing out a few stars and giving the cluster a name. Furthermore, the boundary between a constellation and its surroundings is very much a function of where we draw the lines (or more aptly, how we connect the dots) (Page, 2006: p. 328).

While reality may be divided up into individual heavenly bodies independently of us, it is we who select certain stars and not others as belonging to a given constellation. We could chop up the visible objects in the night sky into constellations in any number of ways. No one of these divisions into constellations would better carve reality at its joints than any other.

It is worth noting that what goes for constellations also goes for national borders, time zones, and many (though perhaps not all) other social realities. There are facts about the existence and structure of the continental land mass of North America that are (plausibly) independent of us. Given our various interests in having nations and keeping time, we chop up the land mass into individual nations and individual time zones. We could have chopped up the land mass into nations and time zones in any number of ways. Some might have been more or less convenient. Some might have made strategic use of natural features (such as mountains or rivers). But to a great extent, none of them would better reflect any true national or time-zone like joints in any reality that is independent of us. I would submit that constellations, like nations and time zones, are among the social realities that are ontologically dependent on us. If humans were to wink out of existence, the heavenly bodies would still be arranged in the sky in a certain fashion, but constellations would cease to exist.

Interestingly, Page is inclined to take rainbows (or at least their stripes) to be further examples of things that are individuatively dependent on us. "Though it may appear that there is a finite number of colour stripes in a rainbow, in reality a rainbow is a smooth spectrum that can be divided into as many stripes as we like" (Page, 2006: p. 328). Whether or not there is a sense in which rainbows or their stripes are individuatively dependent on us, I think it is a mistake to suggest that the stripes of a rainbow are individuatively dependent on us in the way in which constellations are. In the case of constellations, we perceive an arrangement of heavenly bodies in the sky and then group these heavenly bodies in various ways thereby individuating constellations. This is not what is going on in the 
individuation of the stripes of a rainbow. Whether or not it is true to say that "in reality a rainbow is a smooth spectrum", it is certainly not the case that we consciously perceive rainbows as a smooth spectrum and only then chop them into stripes. We consciously perceive the rainbow and its stripes simultaneously. Unlike the case of the night sky and constellations, we are not free to chop up the rainbow into stripes in any number of ways. Instead, our perceptual mechanisms do the chopping prior to the conscious experience of the rainbow. If the stripes in a rainbow are examples of individuatively dependent objects, they depend for their individuation on us in a very different way than do constellations, time zones, or national borders. In fact, the distinction between the way in which the stripes of a rainbow are individuated by us and the ways in which constellations, time zones, and national borders are individuated by us perfectly parallels the distinction noted above between these objects taken as ontologically dependent.

It is difficult to imagine how something could, quite independent of us, be an individual thing when it depends on us for its ontological status. The very idea of something individuatively independent but ontologically dependent would seem to be incoherent. I would submit that individuative independence entails ontological independence. But what about the reverse? Despite the variety of ways in which an object can be individuatively dependent on us, the plausible examples of individuatively dependent objects have all turned out to be ontologically dependent on us (though in different ways). It is thus tempting to conclude that individuative dependence entails ontological dependence. If this is correct, the set of objects that are individuatively dependent is coextensive with the set of objects that are ontologically dependent (and hence with the set of objects that are structurally dependent). It would appear that Page has too hastily dismissed the notions of ontological and structural dependence as irrelevant to the metaphysical realism/antirealism debate.

But what are we to make of Page's explicit denial that individuative dependence entails structural dependence (Page, 2006: p. 332)?

If something is individuatively dependent on us, it does not follow that it is structurally dependent on us as well. Mountain peaks, for example, are individuatively dependent on us, since the number of peaks in a given mountain range depends on how "peak" is defined. ... Of course, it would be absurd to think that the peaks are also structurally dependent on us, that we somehow structure the peaks through some mysterious cognitive faculty (Page, 2006: pp. 332-333). ${ }^{9}$

The answer lies in noting an important ambiguity in the notion of individuation. On one sense of "individuation", individuation is a metaphysical/ontological notion. Something is individuated in this sense if it exists or otherwise has ontologycal status as an individual (This is the sense in which I have been using "individuation" above in arguing that ontological

\footnotetext{
${ }^{9}$ It is worth noting that a similar claim could be made about the structure of time zones, which are plausibly taken to be ontologically dependent on us. The number of time zones depends upon how we chopped the surface of the Earth into time zones. However, once the surface of the Earth is chopped up into time zones, we can consider the structure of the part that constitutes the Pacific time zone. This portion of the surface of the earth would seem to have at least most of its structure (if not its defining borders) quite independent of us. I believe that what I have to say in response to Page's example of mountain peaks will apply mutatis mutandis to time zones.
}

dependence and individuative dependence are coextensive notions). Let us call this sense "metaphysical individuation". On another sense of "individuation", individuation is an epistemic and/or linguistic notion. Something is individuated in this sense if it is singled out for reference by having a singular term or definite description applied to it. Let us call this sense "linguistic individuation".

As I want to use the term, "linguistic individuation" is a success term. Nothing can be linguistically individuated if there is no object that is metaphysically individuated (whether dependently on or independently of us) to serve as the referent of the term or definite description (I make no presumption that any definite description used to linguistically individuate an object accurately describes the object. It is sufficient that the description allows for successful reference to the object). While linguistic individuation entails metaphysical individuation, the reverse is not the case. No doubt, there are many objects that are metaphysically individuated that have not been and likely never will be linguistically individuated by us. Plausible examples include individual rocks on the far side of the moon, most individual examples of extinct species, most individual hydrogen molecules, and the individual sub-portions of the surface of the Earth that might have been but were not in fact picked out as time zones.

With the distinction between metaphysical individuation and linguistic individuation in mind, let us return to Page's example of mountain peaks. Consider a portion of a mountain range that includes a summit and surrounding saddles such that the summit rises 150 feet above its highest surrounding saddle. Call this portion "Mt. X". Let us first suppose that Page's claim is merely that Mt. X can have an independent structure while being dependent on us for its being accurately linguistically individuated as a peak. I would submit that this is not a claim that has any bearing on the debate between metaphysical realists and antirealists. Of course it is true that whether or not "being an individual peak" can accurately be predicated of Mt. X depends on our linguistic conventions (as does its being called "Mt. X"). Whether or not Mt. X is a peak depends upon how we define 'peak'. If we require that a peak be 200 feet higher than any saddle surrounding it, then Mt. X is not a peak. If we allow any summit that is 100 feet or higher than any saddle surrounding it to count as a peak, then Mt. X is a peak. I would be surprised if any philosopher had ever wanted to claim that whether or not a linguistic item is accurately predicated of an individual is something that is independent of us and our use of language. In any case, this is certainly not something that the metaphysical realist must maintain.

However, the question of whether or not "peak" is accurately predicated of Mt. X is a distinct question from whether its metaphysical individuation is in any way dependent on us. If we suppose (as is plausible) that Mt. X is not dependent on us for its metaphysical individuation (i.e., that there would have been a summit in this range rising 150 feet above its highest surrounding saddle even if humans had never existed), it is natural to suppose that Mt. X is structurally independent of us. But this is not a case in which we have a structurally independent object that is metaphysically individuatively dependent on us. If we suppose along with the metaphysical antirealist that Mt. $\mathrm{X}$ is dependent on us for its metaphysical individuation, then, barring an account of how an object can have any structure at all if it lacks ontological status, it is not plausible to agree with Page that its structure is independent of us. I would 
submit that metaphysical individuative dependence, which is the sort of individuative dependence germane to the metaphysical realism/antirealism debate, stands or falls with structural dependence.

\section{Conclusion}

In summary, there is reason to believe that ontological dependence, structural dependence, and the only sort of individuative dependence that is relevant to the metaphysical debate are all coextensive notions. As such, any argument that succeeds in establishing that it is incoherent to suppose that everything is ontologically and/or structurally dependent thereby establishes the incoherence of metaphysical antirealism. To resist this conclusion the metaphysical antirealist has limited options: 1) provide an account of how one and the same thing could be dependent on us for its ontological status as an individual without being dependent on us more generally for its ontological status (thereby rejecting the entailment between metaphysical individuative dependence and ontological de- pendence), 2) provide an account of how one and the same thing could be dependent on us for its ontological status as an individual without being dependent on us for its structure (thereby rejecting the entailment between metaphysical individuative dependence and structural dependence), or 3) tackle the arguments that appear to establish the incoherence of global ontological or global structural dependence head on. In any case, it would appear that the metaphysical antirealist has a significant explanatory burden to meet if he is to defend the viability of his view.

\section{REFERENCES}

Page, S. (2006). Mind-independence disambiguated: Separating the meat from the straw in the realism/anti-realism debate. Ratio, 19, 321-335. doi:10.1111/j.1467-9329.2006.00330.x

Smith, D. C. (2002). The case for metaphysical realism. The Southern Journal of Philosophy, 40, 411-419. doi:10.1111/j.2041-6962.2002.tb01909.x 